\title{
Influences of stretch and curvature on the temperature of stretched cylindrical diffusion flames
}

\author{
Yosuke SUENAGA*, Hideki YANAOKA* and Daisuke MOMOTORI** \\ * Department of Systems Innovation Engineering, Iwate University \\ 4-3-5 Ueda, Morioka, Iwate 020-8551, Japan \\ E-mail: suenaga@iwate-u.ac.jp \\ **Hitachi Koki \\ 1060 Takeda, Hitachinaka, Ibaraki 312-8502, Japan
}

Received 25 April 2016

\begin{abstract}
The structure of a counterflow-type cylindrical diffusion flame was studied experimentally to determine the effect of stretch and curvature. The cylindrical flame used in this study had a concave curvature with respect to the fuel stream. The fuels used were propane and methane, diluted with nitrogen, argon or helium. Diluent gases were used to change the Lewis number, $L e_{f}$, of the fuel. Our results indicated that (1) the fuel was preheated to a high temperature by the concentric inward heat flow from the flame because the flame shape is concave curvature with respect to the fuel flow; (2) at constant flame stretch, flame temperature increased with a decrease in flame radius when $L e_{f}>1$, but decreased when $L e_{f}<1$; and (3) at constant flame radius, flame temperature decreased with increased flame stretch rate when $L e_{f}>1$, but increased when $L e_{f}<1$.
\end{abstract}

Key words : Diffusion flame, Flame temperature, Flame stretch, Flame curvature, Lewis number effect

\section{Introduction}

Since the structure of a turbulent flame can be interpreted as an aggregation of laminar flamelets that undergo distortion (i.e., stretching or contraction) and deformation (i.e., curves) caused by turbulent flow, the influence of flame stretch and curvature on the combustion characteristics have been studied extensively. Researches on diffusion flames include (1) researches on counterflow diffusion flames that are subject only to stretching due to the velocity gradient (Tsuji and Yamaoka, 1967, 1969; Otsuka and Niioka, 1973; Ishizuka and Tsuji, 1981; Smooke et al., 1986; Chelliah et al., 1990; Sung et al., 1995; Chen et al., 2007); (2) experimental and numerical research on convex flames subject to a microjet blown into the center of counterflow diffusion flames (Takagi et al., 1996; Yoshida and Takagi, 1998; Finke and Grunefeld, 2000); and (3) research on cylindrical diffusion flames that stretch in the axial direction by Wang et al. (2007), Hu et al. (2007, 2009), and the authors (2010, 2011).

The cylindrical diffusion flames used in these studies were formed by either supplying fuel from the central axis to the surrounding area in the radial direction and an oxidizer from the surrounding area toward the central axis in a cylindrical coordinate system, or by supplying an oxidizer from the central axis and fuel from the surrounding area. Wang et al. carried out a numerical study of the effects of flame stretch and curvature on the temperature of an $\mathrm{H}_{2}$ - $\mathrm{N}_{2}$ /air flame at radii ranging from 2 - $11 \mathrm{~mm}$ (Wang et al., 2007), and of a $\mathrm{CH}_{4}-\mathrm{N}_{2} /$ air flame in which the stagnation radius $R_{s}$ was held constant at $5 \mathrm{~mm}$ (Wang et al., 2007). Hu et al. also conducted numerical and experimental studies on $\mathrm{H}_{2}-\mathrm{N}_{2}, \mathrm{C}_{3} \mathrm{H}_{8}-\mathrm{N}_{2}$ and $\mathrm{CH}_{4}-\mathrm{N}_{2}$ / air flames when $R_{5}>5 \mathrm{~mm}$ (Hu et al., 2007; Hu and Pitz, 2009). We studied experimentally the extinction characteristics of cylindrical diffusion flames formed by supplying fuel from the central axis to the surrounding area and air from the surrounding area to the central axis (Suenaga et al., 2010, 2011). These cylindrical flames have a concave curvature with respect to the fuel stream, and the Lewis number of the fuel stream is greater than unity. The results obtained from these studies were: (1) the burner used was able to form a cylindrical diffusion flame with good circularity (hence, the flame curvature could be evaluated easily), with a minimum flame 
diameter of approximately $2.5 \mathrm{~mm}$; (2) a flame was formed even at dilution rates that would rule out a counterflow flat diffusion flame; and (3) the stretch rate at extinction increased with decreased flame diameter. In order to clarify the combustion characteristic of a cylindrical diffusion flame that is subject to the effect of stretching and curvature, its flame characteristic should be investigated over a wide range of fuel flow velocity, oxidizer flow velocity and Lewis numbers. This study, therefore, investigated the temperature distribution of flames over a wide range of Lewis numbers of the fuel stream to identify the effects of flame stretch and curvature on flame temperature, which can be considered a measure of combustion intensity.

\section{Experimental setup and procedure}

\subsection{The burner}

Figure 1 shows a schematic of the burner. It consists of a radial-flow nozzle, which was used in a study of a cylindrical premixed flame (Kobayashi and Kitano, 1989), and a stainless steel tube $1.2 \mathrm{~mm}$ in diameter installed along the central axis of the nozzle. The outlet of the nozzle is $10 \mathrm{~mm}$ wide and $12 \mathrm{~mm}$ in diameter, and the oxidizer flows toward the central axis. On the stainless steel tube (or the fuel tube) installed along the central axis, eight 0.3-mm openings were made circumferentially along one line, and 11 such lines with eight openings each were aligned at intervals of $1 \mathrm{~mm}$ in the axial direction. The fuel flows out through these openings in the radial direction. The velocity of the fuel flow $v_{f}$ is defined as the supplied fuel + diluent flow rate divided by the surface area of the $10 \mathrm{~mm}$-long fuel tube including these openings. A stagnation surface was formed between the fuel flow and the oxidizer flow, and a cylindrical diffusion flame was formed in the vicinity of the stagnation surface. To isolate the flame from the ambient air, nitrogen gas was supplied from the top and bottom nozzles of the oxidizer supply outlet. A cooling system and air curtain were installed upstream of the fuel supply opening to prevent the fuel tube from overheating. Propane $\left(\mathrm{C}_{3} \mathrm{H}_{8}\right)$ and methane $\left(\mathrm{CH}_{4}\right)$ were used as fuels, and air was used as the oxidizer. Nitrogen $\left(\mathrm{N}_{2}\right)$, argon $(\mathrm{Ar})$ and helium $(\mathrm{He})$ were used to dilute the fuel flow. The Lewis number of the fuel stream $L e_{f}(=\alpha / D)$ was varied by changing the mixing rate or combination of fuels and diluents. Here $\alpha$ is the thermal diffusivity of the unburned fuel mixture, $D$ is the binary diffusion coefficient of the fuel $\left(\mathrm{CH}_{4}\right.$ or $\left.\mathrm{C}_{3} \mathrm{H}_{8}\right)$ with the diluent $\left(\mathrm{N}_{2}\right.$, Ar or He). The dilution rate $\xi_{f}$ is defined as follows:

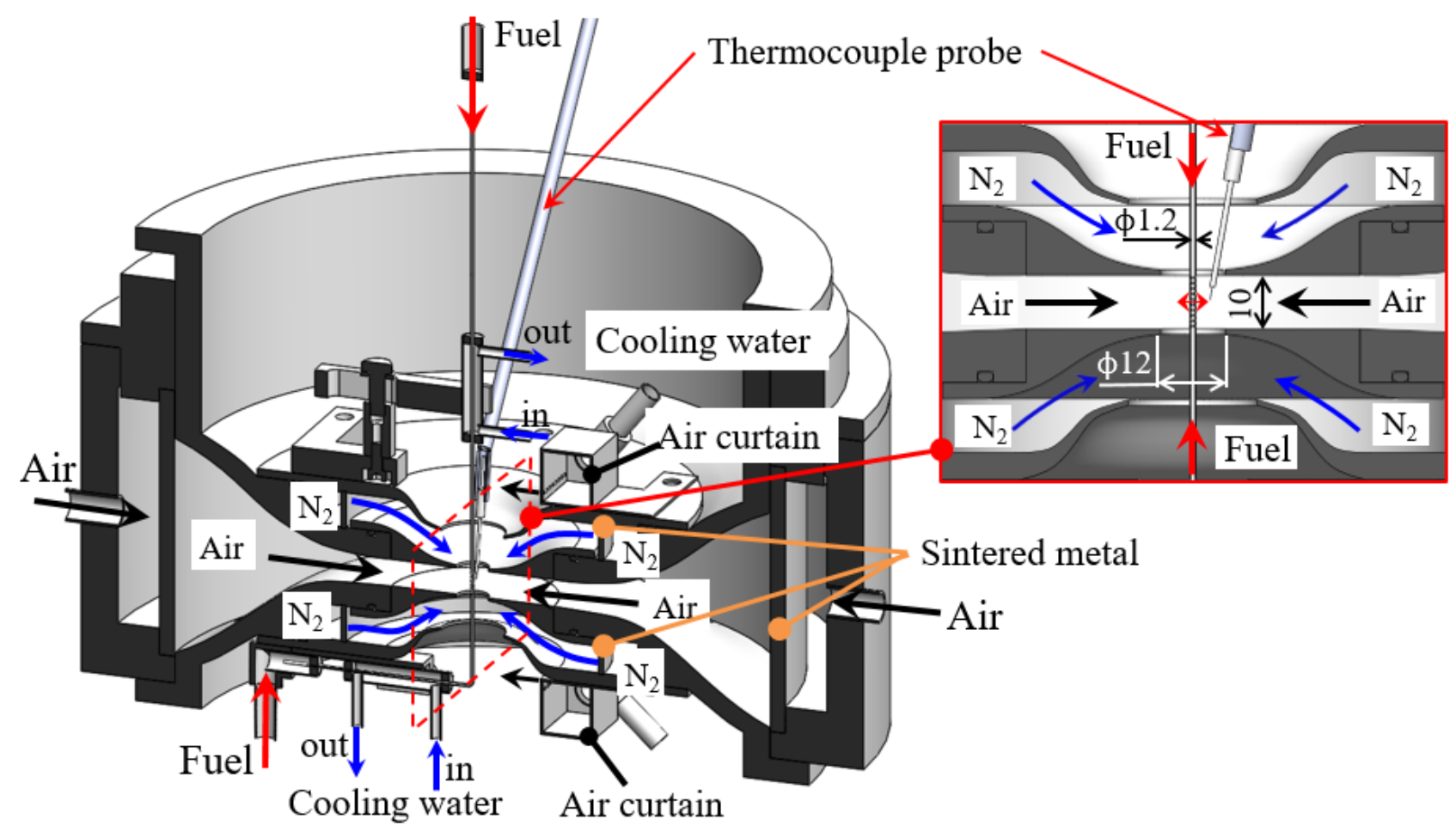

Figure 1. Schematic of the cylindrical diffusion flame burner 
Table 1. Experimental conditions

\begin{tabular}{c|c|c}
\hline \hline Fuel mixture & $\begin{array}{c}\text { Dilution rate of fuel } \\
\xi_{f}[\%]\end{array}$ & $\begin{array}{c}\text { Lewis number } \\
L e_{f}[-]\end{array}$ \\
\hline $\mathrm{C}_{3} \mathrm{H}_{8}-\mathrm{He}$ & 85 & 1.83 \\
\hline $\mathrm{C}_{3} \mathrm{H}_{8}-\mathrm{Ar}$ & 80 & 1.27 \\
\hline $\mathrm{CH}_{4}-\mathrm{He}$ & 50 & 0.85 \\
\hline $\mathrm{CH}_{4}-\mathrm{Ar}$ & 50 & 1.02 \\
\hline $\mathrm{CH}_{4}-\mathrm{N}_{2}$ & 50 & 1.04 \\
\hline $\mathrm{CH}_{4}-\mathrm{N}_{2}$ & 70 & 1.02 \\
\hline
\end{tabular}

${ }^{*} L e_{o}$ is 1.07 (constant) as air is used oxidizer for all cases

${ }^{*} L e_{f}$ and $L e_{o}$ were calculated for $300 \mathrm{~K}$ and $1 \mathrm{~atm}$.

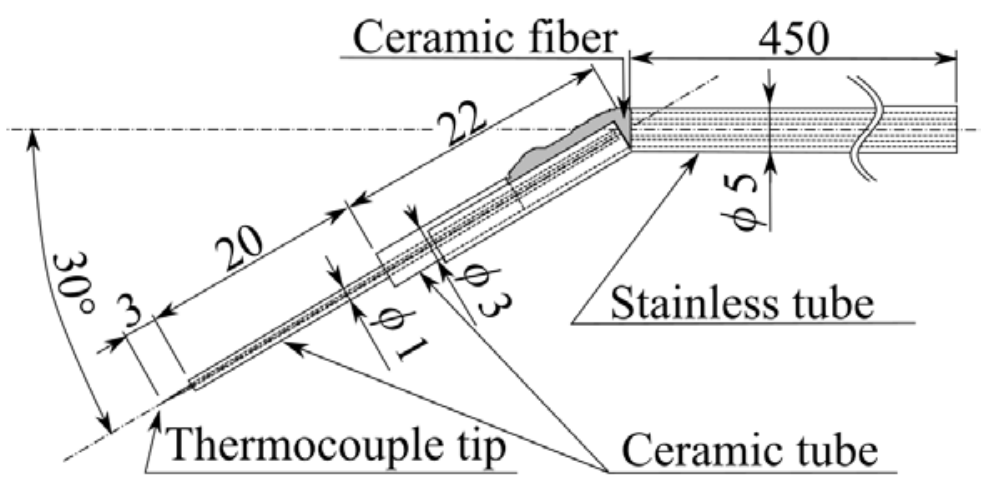

Figure 2. Schematic of the thermocouple probe

$$
\xi_{f}=\frac{q_{d}}{\left(q_{f}+q_{d}\right)} \times 100 \quad[\%]
$$

where $q_{d}$ and $q_{f}$ are the supply flow rates of diluent and fuel gases, respectively. Air as the oxidizer was not diluted. Thus, the Lewis number of the oxidizer stream $L e_{o}$, that is, the ratio of the thermal diffusivity of air to binary coefficient of oxygen with nitrogen, is kept constant at 1.07 .

Table 1 shows the experimental conditions: the dilution rate of fuel-diluent mixtures $\xi_{\text {f }}$, the Lewis number of fuel-diluent mixtures $L e_{f}$ and that of air $L e_{o}$ (Software Tools, Colorado State University, 2013). As shown in this Table, three $L e_{f}$ cases $\left(L e_{f}<1, L e_{f} \approx 1\right.$, and $\left.L e_{f}>1\right)$ were chosen. Considering the effect of buoyancy force, the burner was set such that the central axis faced the same direction as gravity.

\subsection{Flame temperature and radius}

A schematic of the thermocouple probe is shown in Fig. 2. The radial temperature distribution of the cylindrical diffusion flame was measured using a Pt-Rh20\%/Pt-Rh40\% thermocouple $50 \mu \mathrm{m}$ in diameter. The thermocouple is held by a $1 \mathrm{~mm}$ diameter ceramic tube with two holes. A distance from the thermocouple tip to the ceramic tube end is 3 $\mathrm{mm}$. The thermocouple probe is installed on the 3-axis fine-adjustment stage. As shown in Fig.1, the probe is inserted from the upper side of the burner. The temperature was measured exactly in the middle of the central axis of the cylindrical flame with radial distances $r$ ranging from $0.7 \mathrm{~mm}$ to $4.3 \mathrm{~mm}$. Flame temperature $T_{f}$ was the maximum value of the measured temperature distribution. The standard deviation of the temperature $T_{p}$, which was measured in the vicinity of the fuel tube surface, and $T_{f}$ was $\pm 1 \mathrm{~K}$ or less. No temperature collection for the heat losses due to radiation and thermal conduction was made to the output from the thermocouple. Flames at each fuel flow rate and 
oxidizer flow rate were photographed from the underside of the burner using a video camera (frame rate: $60 \mathrm{fps),} \mathrm{and}$ the flame radius $r_{f}$ was determined by analyzing the images taken. The spatial resolution of the photographed images was $0.03 \mathrm{~mm} /$ pixel.

\subsection{Determination of the flame stretch rate}

The stretched cylindrical diffusion flames used in this study were subject to flame stretch effects due to the velocity gradient and flame curvature. In this study, the stretch rates in the fuel side and oxidizer side of the stagnation surface are $\varepsilon_{f}$ and $\varepsilon_{a}$, respectively (Wang et al., 2007):

$$
\begin{aligned}
& \varepsilon_{f}=\pi \frac{\left\{v_{f}\left|R_{f}+\right| v_{a} \mid R_{a} \sqrt{\rho_{a} / \rho_{f}}\right\}}{\left|R_{a}^{2}-R_{f}^{2}\right|} \\
& \varepsilon_{a}=\pi \frac{\left\{v_{a}\left|R_{a}+\right| v_{f} \mid R_{f} \sqrt{\rho_{f} / \rho_{a}}\right\}}{\left|R_{a}^{2}-R_{f}^{2}\right|}
\end{aligned}
$$

where $v$ denotes the nozzle exit velocity; $R$ denotes the nozzle radius; and $\rho$ denotes the nozzle exit density. The subscripts $f$ and $a$ are fuel and air nozzles, respectively. In this study, the cylindrical flames are formed on the air side of the stagnation surface because the stoichiometric mixture fractions $Z_{\text {st }}$ are less than 0.5 . Hence, flame stretch rate $\varepsilon$ is given by formula (3).

\section{Experimental results and discussion}

Our previous research revealed that the heat loss effect induced by the fuel tube affected the extinction characteristics when the fuel flow velocity $v_{f}$ was smaller than $20 \mathrm{~cm} / \mathrm{s}$ (Suenaga et al., 2010, 2011). The figures in this paper except for Fig. 4 therefore show the results of temperature measurements when $v_{f} \geq 25 \mathrm{~cm} / \mathrm{s}$. In order to investigate the influence of flame curvature and stretch rate on the flame temperature, fuel and oxidizer flow velocities, $v_{f}$ and $v_{a}$, were changed variously.

\subsection{Flame structure}

Figure 3 shows the radial distributions of temperature $T$ for a $\mathrm{CH}_{4}-\mathrm{N}_{2} /$ air flame. The dilution rate $\xi_{f}$ was $50 \%$. The air flow velocities $v_{a}$ under experimental conditions (a) and (b) were $30 \mathrm{~cm} / \mathrm{s}$ and $60 \mathrm{~cm} / \mathrm{s}$, respectively, and the fuel flow velocity $v_{f}$ was constant at $25 \mathrm{~cm} / \mathrm{s}$. Under condition (c), $v_{f}$ was $35 \mathrm{~cm} / \mathrm{s}$, and $v_{a}$ was $30 \mathrm{~cm} / \mathrm{s}$, the same as for condition (a). The flame was located at the maximum temperature, and the fuel and air were supplied from the left and right sides of this location, respectively. The maximum temperature is defined as flame temperature $T_{f}$. Under all these conditions, the temperature near the fuel tube surface exceeded $1000 \mathrm{~K}$ and the inflowing fuel was preheated to a high temperature by the flame. This is related to the flame's shape: the heat was transferred convergently to the fuel inside the flame because the flame surrounded the fuel tube.

A flame curvature effect is discussed from the relationship between an inflow mass flux from the reactant flow toward the flame and an outflow heat flux from the flame toward the reactant flow. In this section, we focus on the flame shape and heat transport, the flame curvature effect is discussed in the next section. Based on the results of conditions (a) and (b), we now observe the influence of value $v_{a}$ on flame structure. Under both conditions, when $v_{a}$ was greater, flame radius $r_{f}$ became smaller. In this figure, it is found that the temperature in the vicinity of the fuel tube for smaller flame radius is higher than that for larger flame radius. It is considered that the heat from the flame is transferred convergently to the fuel inside the flame, and that this preheating effect due to the convergent transfer of heat is strengthened as $r_{f}$ decreases. Aside from these results, in the velocity range where the temperature could be measured, when $v_{f}$ was kept constant, $r_{f}$ reduced with increased $v_{a}$, and the temperature of the fuel flow side increased. It is thought that the fuel preheating effect due to the concentric inward heat flow from the flame was strengthened when $r_{f}$ decreases.

We will now consider the influence of value $v_{f}$ on flame structure, based on the results for conditions (a) and (c). Under both conditions, obvious change in $r_{f}$ was not observed when $v_{f}$ increased, but when $v_{f}$ was large, the temperature 


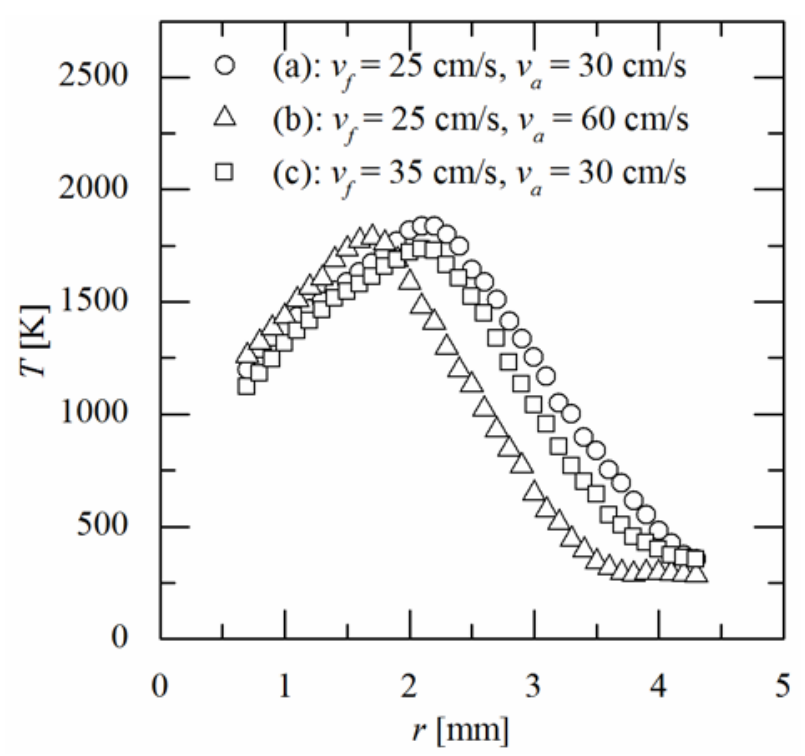

Figure 3. Radial distributions of temperature $T$ for $\mathrm{CH}_{4}-\mathrm{N}_{2} /$ air flame at the dilution rate of the fuel stream $\xi_{f}=50 \%$. $v_{f}$ and $v_{a}$ are the velocities of fuel and air streams, respectively.

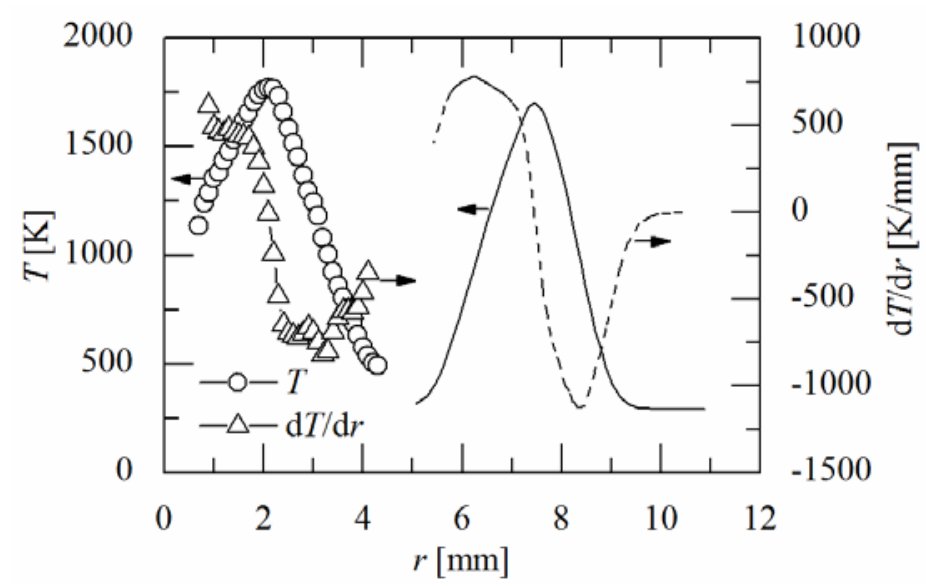

Figure 4. Radial distributions of temperature $T$ and its gradient $\mathrm{d} T / \mathrm{d} r$ for $\mathrm{CH}_{4}-\mathrm{N}_{2}$ /air flame. Stretch rates $\varepsilon$ and the dilution rate of fuel stream $\xi_{f}$ in this study are the same as the numerical results in Hu and Pitz's study (2009), respectively, which are $\varepsilon=122 \mathrm{~s}^{-1}$ and $\xi_{f}=70 \%$. Open symbols show the results of this study, and solid and dashed curves show the results in $\mathrm{Hu}$ and Pitz's study.

near the fuel tube surface was low. Increased $v_{f}$ thus exerted a cooling effect on the fuel stream near the fuel tube surface by reducing the fuel preheating effect generated by the concentric inward heat flow from the flame.

Figure 4 shows the radial distribution of temperature $T$ and its gradient $\mathrm{d} T / \mathrm{d} r$ for $\mathrm{CH}_{4}-\mathrm{N}_{2} /$ air flames. $v_{f}$ and $v_{a}$ were the same at $20 \mathrm{~cm} / \mathrm{s}$, and $\xi_{f}$ was $70 \%$. For comparison, the results of Hu and Pitz's study (2009) on cylindrical diffusion flames are presented in the figure. The open symbols in the figure show the results of this study and the solid and dashed curves show those of Hu and Pitz. These two flame stretch rates are the same as $122 \mathrm{~s}^{-1}$. Due to the different fuel tube diameters $\left(1.2 \mathrm{~mm}\right.$ and $6.4 \mathrm{~mm}$ ), flame radius $r_{f}$ of this study is much smaller than that in Hu and Pitz's study, and the temperature near the fuel tube surface is much higher than theirs. However, in the region near the fuel tube surface, while $\mathrm{d} T / \mathrm{d} r$ in the study by Hu and Pitz decreased monotonically as $r$ decreased, $\mathrm{d} T / \mathrm{d} r$ for our cylindrical flame increased. Nevertheless, the flame temperatures in these studies are almost the same. Our previous research revealed that the extinction stretch rate increased as the flame radius decreased (Suenaga et al., 2010, 2011). As shown in conditions (a) and (b) in Fig. 3, the temperature of the fuel stream in the vicinity of the fuel tube surface was higher 


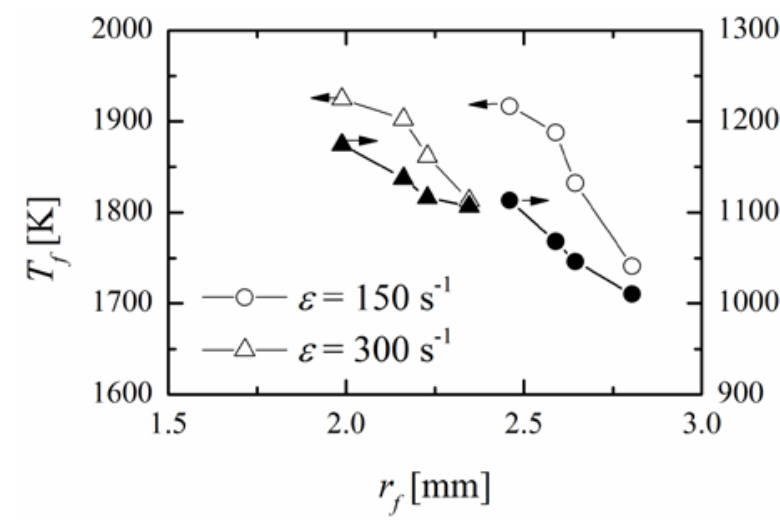

(a) $\mathrm{C}_{3} \mathrm{H}_{8}$-He/air flame $\left(\xi_{f}=85 \%, L e_{f}>1\right)$

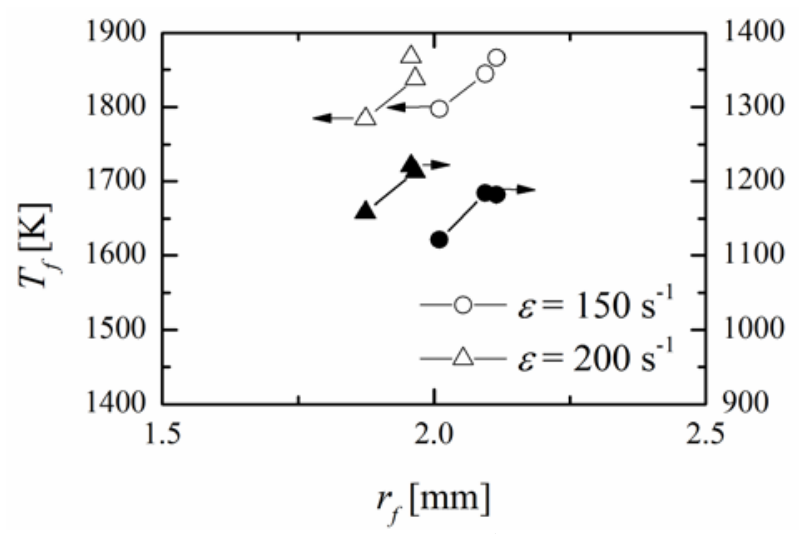

(c) $\mathrm{CH}_{4}-\mathrm{N}_{2} /$ air flame $\left(\xi_{f}=50 \%, L e_{f} \approx 1\right)$

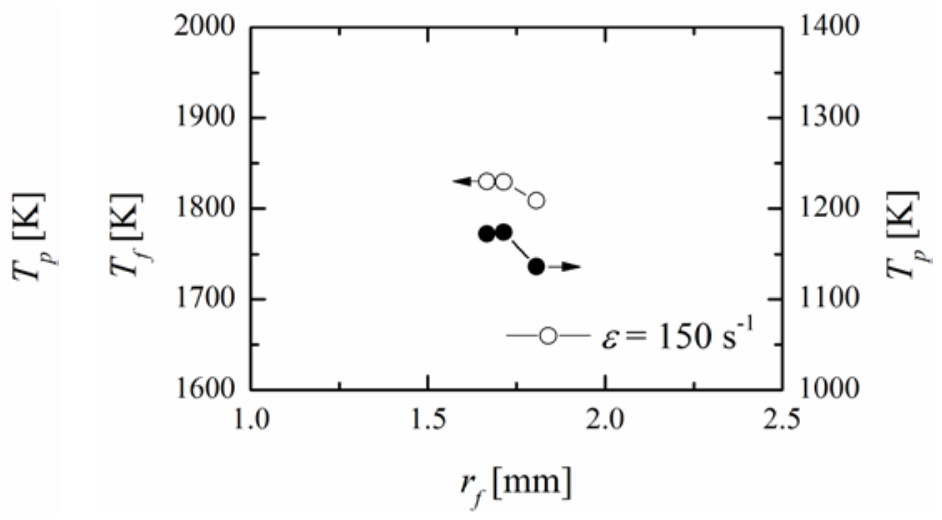

(b) $\mathrm{C}_{3} \mathrm{H}_{8}$-Ar/air flame $\left(\xi_{f}=80 \%, L e_{f}>1\right)$

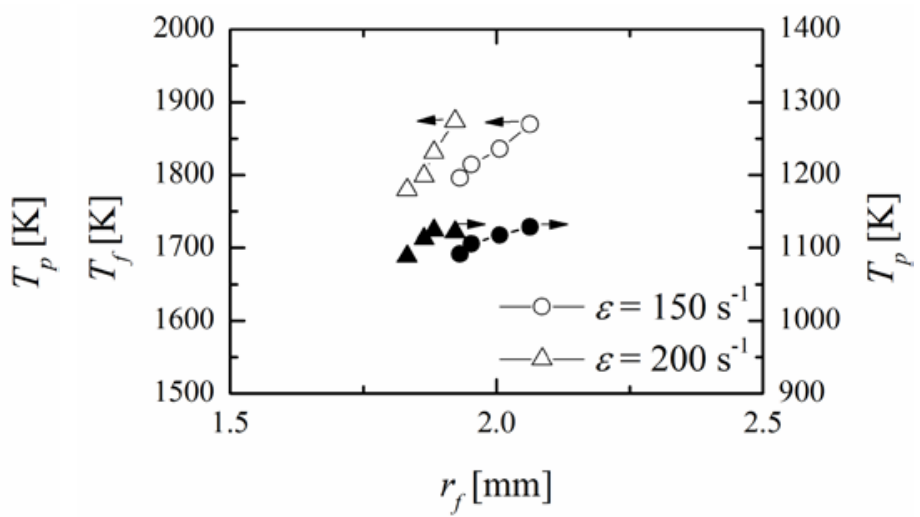

(d) $\mathrm{CH}_{4}$-Ar/air flame $\left(\xi_{f}=50 \%, L e_{f} \approx 1\right)$

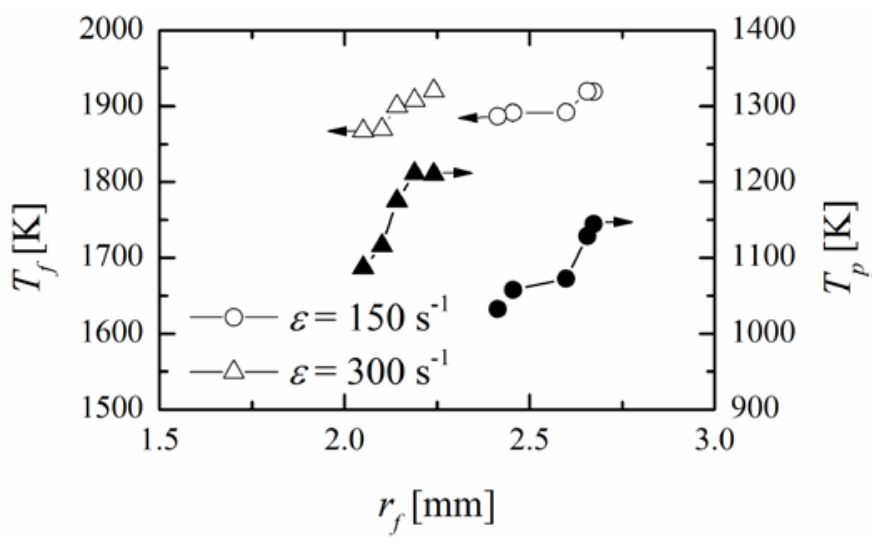

(e) $\mathrm{CH}_{4}$-He/air flame $\left(\xi_{f}=50 \%, L e_{f}<1\right)$

Figure 5. Influences of flame radius $r_{f}$ on flame temperature $T_{f}$ and fuel temperature $T_{p}$ near the fuel tube surface. $\xi_{f}$ and $L e_{f}$ are the dilution rate and Lewis number of the fuel stream, respectively. $\varepsilon$ is the stretch rate.

for a smaller flame radius. It is considered that the fuel preheating effect strengthens the flame due to the decrease in flame radius and thus increases the extinction stretch rate.

\subsection{Influence of flame radius on flame temperature and on inflowing fuel flow temperature}

Figure 5 shows the influence of flame radius $r_{f}$ on flame temperature $T_{f}$ and fuel temperature $T_{p}$, which was measured $0.1 \mathrm{~mm}$ downstream with the fuel tube surface exactly in the middle of the central axis. Stretch rate $\varepsilon$ was kept constant. Figures 5 (a), 5 (b), 5 (c), 5 (d) and 5 (e) show the results for a $\mathrm{C}_{3} \mathrm{H}_{8}-\mathrm{He} /$ air flame $\left(\xi_{f}=85 \%, L e_{f}>1\right)$, a $\mathrm{C}_{3} \mathrm{H}_{8}$-Ar/air flame $\left(\xi_{f}=80 \%, L e_{f}>1\right)$, a $\mathrm{CH}_{4}-\mathrm{N}_{2} /$ air flame $\left(\xi_{f}=50 \%, L e_{f} \approx 1\right)$, a $\mathrm{CH}_{4}$-Ar/air flame $\left(\xi_{f}=50 \%, L e_{f} \approx 1\right)$ 
and a $\mathrm{CH}_{4}$-He/air flame ( $\left.\xi_{f}=50 \%, L e_{f}<1\right)$, respectively, where $L e_{f}$ is the Lewis number of the fuel stream. In Figs. 5 (a) and 5 (b) for $L e_{f}>1$, both $T_{f}$ and $T_{p}$ increased with decreased $r_{f}$, while in Figs. 5 (c), 5 (d) and 5 (e) for $L e_{f} \approx 1$ and $L e_{f}<$ $1, T_{f}$ and $T_{p}$ decreased with decreased $r_{f}$. In this study, since the oxidizer was not diluted-only the fuel gases were diluted - we will discuss the results obtained, focusing on the transfer characteristics of the heat and reactant inside the flame. The heat from the flame was transferred convergently to the fuel inside the flame, whereas the fuel was transferred divergently from the fuel flow to the flame front. This preheating effect due to the convergent transfer of heat strengthened the flame, whereas the divergent transfer of fuel weakened it. Therefore, when $L e_{f}>1$, the flame was strengthened, and when $L e_{f}<1$, it was weakened. As a result, a decrease in $r_{f}$ increased $T_{p}$ and $T_{f}$ when $L e_{f}>1$ but decreased them when $L e_{f}<1$. Wang et al. have numerically studied the characteristics of $\mathrm{H}_{2}-\mathrm{N}_{2}$ /air cylindrical diffusion flames for flame radii ranging from 2 - $11 \mathrm{~mm}$ (Wang et al., 2007). The study by Wang et al. showed that the flame temperature decreased with a decrease in the flame radius when the flame front had a concave curvature with respect to the fuel side; and the flame temperature increased with a decrease in the flame radius when the flame front had a convex curvature. Considering that $L e_{f}$ of the $\mathrm{H}_{2}-\mathrm{N}_{2}$ mixture is less than unity, the results obtained in this study qualitatively agree with those of Wang et al.'s study. Regarding the results of the $\mathrm{CH}_{4}-\mathrm{N}_{2} /$ air flame and $\mathrm{CH}_{4}$-Ar/air flame $\left(L e_{f} \approx 1\right)$, a simple theoretical prediction is that the combustion phenomenon is reversed at the point where the Lewis number Le is 1 , and that a neutral phenomenon can be obtained at that point, i.e., the flame temperature is not affected by the stretch rate. As shown in Figs. 5 (a) and 5 (b) and Fig. 5 (e), the results for $L e_{f}>1$ and $L e_{f}<1$ were consistent with the theoretical prediction because $L e_{f}$ deviated far from unity. However, the results in Figs. 5 (c) and 5 (d) for $L e_{f} \approx 1$ were not as predicted. This may be because $L e$ was estimated in the initial state at a position away from the flame. We also estimated the influence of the temperature on the Lewis number of the fuel stream, since the temperature near the fuel tube surface was very high. However, the variation of Lewis number with gas temperature is relatively small as long as the mixture fraction of fuel and diluent was same. Thus, it can be considered that the change of Lewis number by the fuel-mixture preheating affects little on the results. To clarify the reason for this finding, further investigation is necessary.

\subsection{Influence of the flame stretch rate on flame temperature and on inflowing fuel flow temperature}

Figures 6 (a), 6 (b), 6 (c), 6 (d) and 6 (e) show the influence of flame stretch rate $\varepsilon$ on flame temperature $T_{f}$, and fuel temperature $T_{p}$ measured in the vicinity of the fuel tube surface, for a $\mathrm{C}_{3} \mathrm{H}_{8}-\mathrm{He} / \mathrm{air}$ flame and a $\mathrm{C}_{3} \mathrm{H}_{8}-\mathrm{Ar} / \mathrm{air}$ flame $\left(L e_{f}>1\right)$, a $\mathrm{CH}_{4}-\mathrm{N}_{2} /$ air flame and a $\mathrm{CH}_{4}$-Ar/air flame $\left(L e_{f} \approx 1\right)$, and a $\mathrm{CH}_{4}-\mathrm{He}$ /air flame $\left(L e_{f}<1\right)$, respectively, the same as in Fig. 5. The flame radius $r_{f}$ was kept constant. Figures 6 (a) and 6 (b) show that for $L e_{f}>1, T_{f}$ and $T_{p}$ decreased as $\varepsilon$ increased, while in Figs. 6 (c), 6 (d) and 6 (e) for $L e_{f} \approx 1$ and $L e_{f}<1$, the tendency is seen to be reversed. Generally, in investigations of the Lewis number's effect on the stagnation flow flame, the outflow heat flux and inflow mass flux through the stream tube wall are considered. And also, the numerical study of Wang et al. (2007) indicates that the stretched cylindrical diffusion flames become thinner and the flame curvature effect becomes smaller with the increase in the stretch rate. Therefore, we will discuss the results from the ratio of flame thickness $\delta_{f}$ to flame radius $r_{f}$ and from the outflow heat flux and inflow mass flux through the stream tube wall. $\delta_{f}$ is inversely proportional to the square root of flame stretch rate so as the stretch rate increases, $\delta_{f}$ decreases (Sung et al. 1995). The curvature effect on preferential diffusion depends on $\delta_{f} / r_{f}$ (Wang et al., 2007). As mentioned in the section 3.2, when $L e_{f}>1$, concave curvature towards the fuel stream increases the flame temperature due to the outflow heat flux exceeds the inflow mass flux rate. For constant $r_{f}$ at low stretch rate, the curvature effect is strong because $\delta_{f} / r_{f}$ is large and the temperature is increased by curvature. As the stretch rate increases, $\delta_{f} / r_{f}$ is reduced and the flame temperature reduces due to the diminished effect of curvature on the preferential diffusion. In addition, since the outflow heat flux through stream tube wall exceeds inflow mass flux rate as $\varepsilon$ increases, the flame is weakened, resulting in a decrease in $T_{f}$. When $L e_{f}<1$, as $\varepsilon$ increases, since $\delta_{f} / r_{f}$ is reduced and the flame curvature effect is weakened, the flame temperature increases. And then, since the outflow heat flux through stream tube wall becomes smaller than inflow mass flux rate as $\varepsilon$ increases, the flame is strengthened, resulting in a increase in $T_{f}$. According to the numerical simulation of $\mathrm{H}_{2}-\mathrm{N}_{2} / a i r$ flame by Wang et al. (2007), when the flame front is concave with respect to the fuel stream, the flame temperature first increases as the stretch rate increases and then it begins decreasing at a certain stretch rate. Although the fuel used is different, the results of this study for $L e_{f}<1$ agree qualitatively with their numerical results in the range over which the stretch rate is less than $500 \mathrm{~s}^{-1}$. In Figs. 6 (c), 6 (d) and 6 (e), although $T_{f}$ increases monotonically as $\varepsilon$ increases, $T_{f}$ begins decreasing at some point if $\varepsilon$ increases further. This is probably because the residence time of reactants in the flame zone falls with increased $\varepsilon$, resulting in incomplete combustion. $T_{f}$ will reach its maximum value against $\varepsilon$ in this case, as the results for $\mathrm{H}_{2}-\mathrm{N}_{2} /$ air flames by Wang et al. also show. 


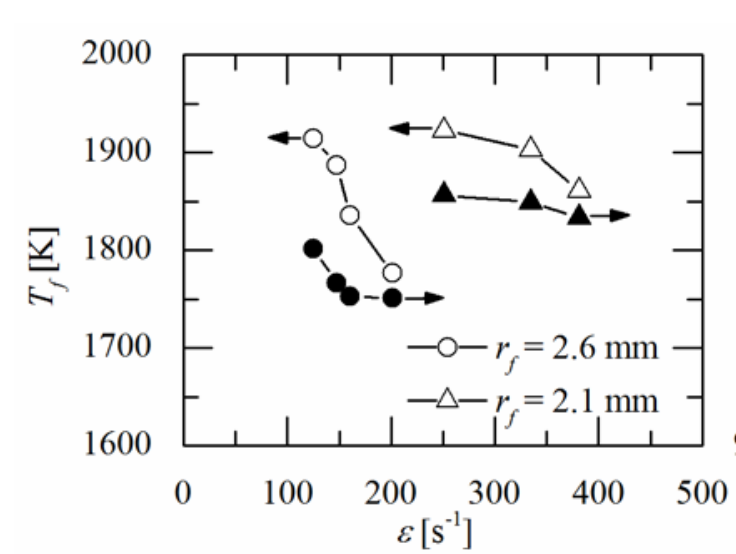

(a) $\mathrm{C}_{3} \mathrm{H}_{8}$-He/air flame $\left(\xi_{f}=85 \%, L e_{f}>1\right)$

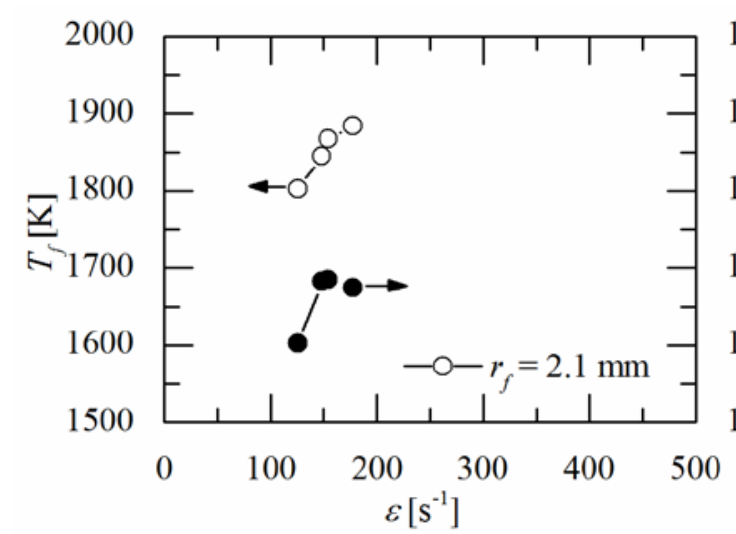

(c) $\mathrm{CH}_{4}-\mathrm{N}_{2} /$ air flame $\left(\xi_{f}=50 \%, L e_{f} \approx 1\right)$

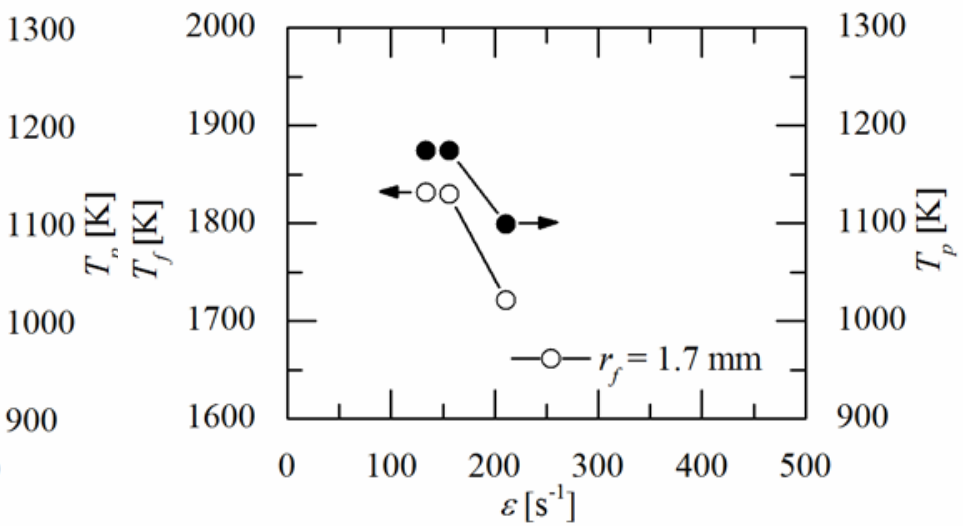

(b) $\mathrm{C}_{3} \mathrm{H}_{8}$-Ar/air flame $\left(\xi_{f}=80 \%, L e_{f}>1\right)$
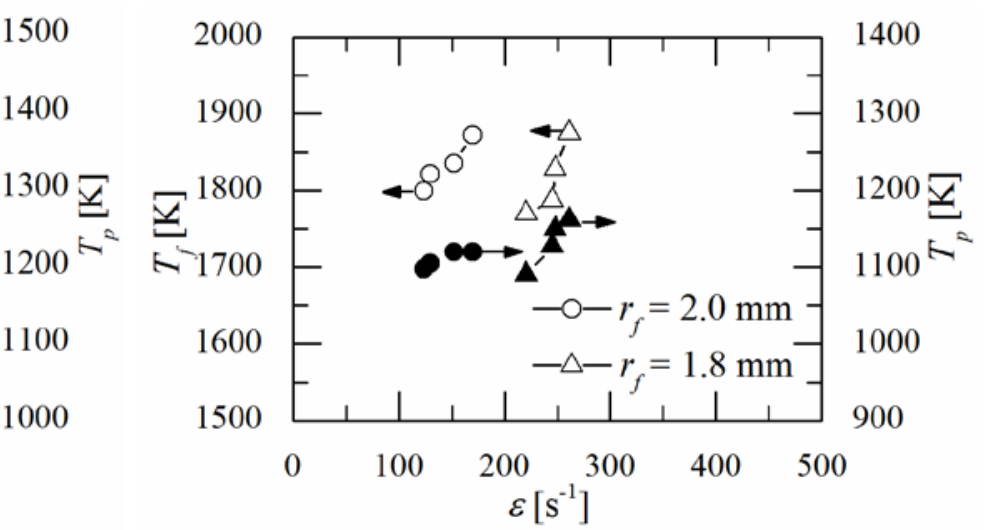

(d) $\mathrm{CH}_{4}$-Ar/air flame $\left(\xi_{f}=50 \%, L e_{f} \approx 1\right)$

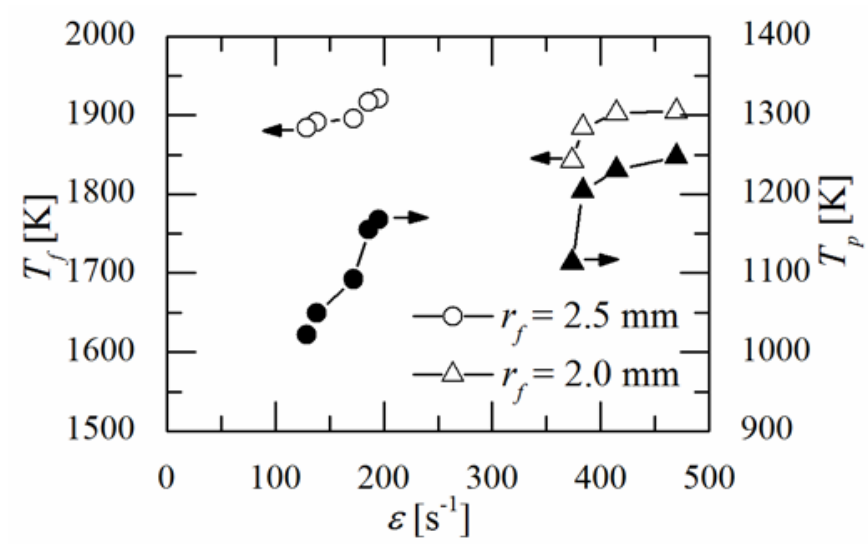

(e) $\mathrm{CH}_{4}$-He/air flame $\left(\xi_{f}=50 \%, L e_{f}<1\right)$

Figure 6. Influences of stretch rate $\varepsilon$ on flame temperature $T_{f}$ and fuel temperature $T_{p}$ near the fuel tube surface. $\xi_{f}$ and $L e_{f}$ are the dilution rate and Lewis number of the fuel stream, respectively. $r_{f}$ is the flame radius.

\section{Conclusions}

Using cylindrical diffusion flames with good circularity, we investigated experimentally the influence of the radius and stretch rate of the flame on the flame temperature and the fuel temperature near the fuel tube surface. The fuel and air flow velocities and the Lewis number of the fuel stream were varied. The fuel was supplied toward the surrounding area from the central axis and air was supplied in the reverse direction to form a flame. $\mathrm{C}_{3} \mathrm{H}_{8}$ or $\mathrm{CH}_{4}$ were used as fuel, 
and air was used as the oxidizer. To change the Lewis number of the fuel stream, fuels were diluted with $\mathrm{N}_{2}$, Ar or He gases. The obtained results are summarized below.

(1) The heat from the cylindrical flame was transferred convergently to the inside of the flame and divergently to the outside. As a result, the fuel supplied from the inside was preheated to a high temperature.

(2) While stretch rate $\varepsilon$ was kept constant, flame temperature $T_{f}$ and fuel temperature $T_{p}$ measured near the fuel tube surface increased with a decrease in the flame radius $r_{f}$ when the Lewis number of fuel stream $L e_{f}$ was greater than unity. When $L e_{f}$ was below unity, this tendency was reversed.

(3) With $r_{f}$ kept constant, $T_{f}$ and $T_{p}$ decreased with increased $\varepsilon$ when $L e_{f}$ was larger than unity. This tendency was reversed when $L e_{f}$ was below unity.

\section{References}

Chelliah, H.K., Law, C.K., Ueda, T., Smooke, M.D. and Williams, F.A., An experimental and theoretical investigation of the dilution, pressure and flow-field effects on the extinction condition of methane-air-nitrogen diffusion flames, Proceeding of the Combustion Institute, Vol.23 (1990), pp.503-511.

Chen, R.H., Chaos, M. and Kothawala, A., Lewis number effects in laminar diffusion flames near and away from extinction, Proceeding of the Combustion Institute, Vol.31 (2007), pp.1231-1237.

Finke, H. and Grunefeld, G., An experimental investigation of extinction of curved laminar hydrogen diffusion flames, Proceeding of the Combustion Institute, Vol.28 (2000), pp.2133-2140.

Hu, S., Wang, P., Pitz, R.W. and Smooke, M.D., Experimental and numerical investigation of non-premixed tubular flames, Proceeding of the Combustion Institute, Vol.31 (2007), pp.1093-1099.

Hu, S. and Pitz, R.W., Structural study of non-premixed tubular hydrocarbon flames, Combustion and Flame, Vol.156 (2009), pp.51-61.

Ishizuka, S. and. Tsuji, H., An experimental study of effect of inert gases on extinction of laminar diffusion flames, Proceeding of the Combustion Institute, Vol.18 (1981), pp.695-703.

Kobayashi, H. and Kitano, M., Extinction characteristics of a stretched cylindrical premixed flame, Combustion and Flame, Vol.76 (1989), pp.285- 295.

Otsuka, Y. and Niioka, T., The one-dimensional diffusion flame in a two-dimensional counter-flow burner, Combustion and Flame, Vol.21 (1973), pp.163-176.

Smooke, M.D., Puri, I.K. and Seshadri, K., A comparison between numerical calculations and experimental measurements of the structure of a counterflow diffusion flame burning diluted methane in diluted air, Proceeding of the Combustion Institute, Vol.21 (1986), pp.1783-1792.

Software Tools, Colorado State University, < http://navier.engr.colostate.edu/ dandy/code/ >. (accessed on 15 January, 2013)

Suenaga, Y., Kitano, M. and Yanaoka, H., Extinction of Cylindrical Diffusion Flame, Transactions of the Japan Society of Mechanical Engineers, Series B, Vol.76, No.770 (2010), pp.1558-1563 (in Japanese).

Suenaga, Y., Kitano, M. and Yanaoka. H., Extinction of Cylindrical Diffusion Flame, Journal of Thermal Science and Technology, Vol.6, No.3 (2011), pp.323-332.

Sung, C.J., Liu, J.B. and Law, C.K., Structural response of counterflow diffusion flames to strain rate variations, Combustion and Flame, Vol.102 (1995), pp.481-492.

Takagi, T., Yoshikawa, Y., Yoshida, K., Komiyama, M. and Kinoshita, S., Studies on strained non-premixed flames affected by flame curvature and preferential diffusion, Proceeding of the Combustion Institute, Vol.26 (1996), pp.1103-1110.

Tsuji, H. and Yamaoka, I., The counterflow diffusion flame in the forward stagnation region of a porous cylinder, Proceeding of the Combustion Institute, Vol.11 (1967), pp.979-984.

Tsuji, H. and Yamaoka, I., The structure of counterflow diffusion flames in the forward stagnation region of a porous cylinder, Proceeding of the Combustion Institute, Vol.12 (1969), pp.997-1005.

Wang, P., Hu, S. and Pitz, R.W., Numerical investigation of the curvature effects on diffusion flames, Proceeding of the Combustion Institute, Vol.31 (2007), pp.989- 996. 
Suenaga, Yanaoka and Momotori, Journal of Thermal Science and Technology, Vol.11, No.2 (2016)

Yoshida, K. and Takagi, T., Transient local extinction and reignition behavior of diffusion flames affected by flame curvature and preferential diffusion, Proceeding of the Combustion Institute, Vol.27 (1998), pp.685-692. 